\title{
ESCRITAS E REFLEXÕES DE SI: memorial como dispositivo autoformativo
}

\section{ESCRITAS Y REFLEXIONES DE SI: memorial como dispositivo autorformador}

\section{SELF WRITING AND REFLECTIONS: memorial instrument formative author}

\author{
Fabrício Oliveira da Silva ${ }^{1}$ \\ ORCID: https://orcid.org/0000-0002-7962-7222 \\ Rita de Cassia Menezes de Mattos ${ }^{2}$ \\ ORCID: https://orcid.org/0000-0001-5881-0784
}

\section{Resumo}

$\mathrm{O}$ artigo busca compreender a contribuição do memorial como dispositivo metodológico que contribui na/para a formação docente. A pesquisa se configura numa abordagem qualitativa que emprega análise biográfica desenvolvida com a intenção de compreender a produção (auto)biográfica como recurso (auto)formativo de/para formação docente. Utiliza-se como recolha de informações as escritas de um memorial de formação produzido por uma professora em formação continuada em curso de pós-graduação. As concepções se ancoram nos fundamentos de Diehl (2002), Souza (2006), Gomes (2008), Josso (2010), Tardif(2012) e Silva (2020). Os resultados sugerem que as discussões em torno da pesquisa (auto)biográfica no campo educacional possibilita ao sujeito produzir sentido sobre o processo de formação e sobre as aprendizagens desenvolvidas no percurso formativo. Foi possível evidenciar que a utilização da escrita (auto)biográfica constitui-se em um interessante instrumento formativo pessoal/profissional.

Palavras-chave: Memória. Formação Docente. Narrativa (auto)biográfica.

\section{Resumen}

El artículo busca entender la contribución del memorial como un dispositivo metodológico que contribuye a/para la formación del profesorado. La investigación se configura en un enfoque cualitativo que emplea un análisis biográfico desarrollado con la intención de comprender la producción (auto) biográfica como un recurso (auto) formativo para / para la formación del profesorado. Se utiliza como dispositivo de investigación el memorial de capacitación producido por una maestra en educación continua en un curso de posgrado.

\footnotetext{
${ }^{1}$ Doutor em Educação. Professor Adjunto do Departamento de Educação - Área Prática de Ensino. Professor Permanente do Programa de Pós-Graduação em Educação - PPGE/UEFS. E-mail: fosilva@uefs.br

2 Estudante do Programa de Pós-Graduação em Educação - PPGE/UEFS. E-mail: kassiamatos@hotmail.com
}

Como referenciar este artigo:

SILVA, F. O.; MATTOS, R. C. M. Escritas e reflexões de si: memorial como dispositivo autoformativo. 
Los conceptos están anclados en los fundamentos de Diehl (2002), Souza (2006), Gomes (2008), Josso (2010), Tardif (2012) y Silva (2020). Los resultados sugieren que las discusiones en torno a la investigación autobiográfica en el campo educativo permiten al sujeto producir significado sobre el proceso de formación y sobre el aprendizaje desarrollado en el camino formativo. Fue posible demostrar que el uso de la escritura auto biográfica es una herramienta de capacitación personal/profesional interesante.

Palabras clave: Memoria. Formación docente. Narrativa autobiográfica.

\title{
Abstract
}

The article seeks to understand the memorial's contribution as a methodological device that contributes to / for teacher education. The research is configured in a qualitative approach that employs a biographical analysis developed with the intention of understanding the (auto) biographical production as a (auto) formative resource for / for teacher training. The collection of information from a training memorial produced by a teacher in continuing education in a postgraduate course is used to collect information. The concepts are anchored in the foundations of Diehl (2002), Souza (2006), Gomes (2008), Josso (2010), Tardif (2012) and Silva (2020). The results suggest that the discussions around (auto) biographical research in the educational field allow the subject to produce meaning about the training process and about the learning developed in the formative path. It was possible to show that the use of (auto) biographical writing is an interesting personal / professional training tool.

Keywords: Memory. Teacher Education. Narrative (auto) biographical.

\section{INTRODUÇÃO}

\author{
"Eu quase que nada não sei. Mas desconfio \\ de muita coisa” (Guimarães Rosa, 1993)
}

Desconfiar de muita coisa, na discussão que se desenvolve nesse texto, implica em se reconhecer o potencial da narrativa para gerar o conhecido, aquilo que para Rosa (1993) se concretiza no quase nada é não sabido. Atualmente a utilização do trabalho (auto)biográfico no contexto educacional, especialmente nos cursos de formação continuada, tem se revelado um importante dispositivo na/para (re)construção da identidade docente e autoafirmação profissional, por entender que, conforme Souza (2007a, p.4), “as implicações pessoais e as marcas construídas na trajetória individual/coletiva, expressas nos relatos escritos, revelam aprendizagens da formação e sobre a profissão". 
"Baseando-se na ideia de que somos seres históricos e que nossas ações e pensamento mudam no tempo, [...] produzindo a nós mesmos e a cultura a que pertencemos" (ARANHA, 2006, p.19), o objetivo deste artigo é compreender a importância do trabalho (auto)biográfico e sua relação com o saber docente e a formação profissional, bem como discutir sobre aspectos que apontam o trabalho com histórias de vida como dispositivo (auto)formativo, sobretudo nos cursos de formação de professores para o exercício profissional docente nas instituições de ensino superior.

A compreensão das práticas, saberes dos professores, bem como dos processos de formação pelos quais transitam é cada vez mais necessária no campo educacional. Para além de querer saber como as ações formativas e de práticas educativas são realizadas no cenário educacional, há uma necessidade de compreender os sentidos que os professores atribuem a tal feitos. Nesse aspecto, as narrativas têm sido tomadas, em diversas abordagens teórico-metodológicas, como dispositivos centrais que consideram o sujeito como protagonista na produção de sentidos para aquilo que ele vivencia, principalmente em se tratando dos processos de formação. Diante de tal perspectiva, a (auto)biografia tem se revelado como uma interessante abordagem para desenvolvimento de pesquisas em educação, exatamente pela centralidade nas experiências de vida, formação e atuação profissional que são significadas e ressignificadas pela ação de narrar que os próprios professores produzem.

Neste trabalho, utilizaremos excertos narrativos de um memorial construído no decurso de uma formação em um curso de pós-graduação em Docência do Ensino Superior, oferecido por uma instituição privada, localizada no interior do estado da Bahia, que oferta cursos de pós-graduação e envolve os mais variados profissionais em diversas áreas do conhecimento. Neste sentido, a experiência vivenciada no presente estudo retrata a contribuição do memorial como dispositivo (auto)formativo num processo de formação docente para o exercício no ensino superior, uma vez que a escrita de um memorial remete às reminiscências, às histórias que constituem o sujeito, a rememorar o que estava adormecido na memória. Neste sentido, discutir o papel da memória na formação é imprescindível para pensarmos no professor em que estamos nos constituindo, nos transformando. 
Assim sendo, trata-se de uma pesquisa qualitativa, que se ancora na perspectiva (auto)biográfica, tendo como dispositivo de recolha de informações o memorial, por meio do qual as narrativas serão analisadas a partir do movimento interpretativo compreensivo. Em tal paradigma metodológico, faz-se emergir da própria narrativa os sentidos que o sujeito imprime ao se inscrever na sua própria história, significando e ressignificando suas lembranças, vivências e experiências.

1 NUMA FORMAÇÃO DOCENTE, É PRECISO FALAR DA MEMÓRIA...

A memória é escrita num tempo, um tempo que permite deslocamento sobre as experiências. (SOUZA, 2007, p.4)

O tempo ressignifica o vivido, o experienciado, gerando a lembrança de vivências, que se consolidam como acontecimentos significativos e que, por tal, se singularizam e constituem o sujeito da experiência. Assim, as experiências nascem e encontram assento na memória que, pelo tempo, deslocam-se produzindo outros tantos sentidos para o vivido e o ressignificado. De acordo com Chauí (1997, p.126) os antigos gregos consideravam a memória uma identidade sobrenatural ou divina: “[...] era a deusa Mnemosyne, mãe das Musas [...]", pois:

A deusa Memória dava aos poetas e adivinhos o poder de voltar ao passado e de lembrá-lo para a coletividade. Tinha o poder de conferir imortalidade aos mortais, pois quando o artista ou historiador registram em suas obras a fisionomia, os gestos, os atos, os feitos e as palavras de um humano, este nunca será esquecido e, por isso, tornando-se memorável, não morrerá jamais. (CHAUÍ, 1997, p.126).

Assim, a memória então seria uma evocação do passado e o homem que teria capacidade de guardá-la.

Como afirma Gomes (2008, p.40), o principal meio cultural de reprodução é a transmissão de significados culturais não só de geração para geração, mas no espaço de uma mesma geração, ou seja, no cotidiano. Pode-se, então, a partir desse aspecto, relacionar a transmissão de signos culturais à memória, pois, segundo Horta (2005, p.310, grifo do autor), "os quadros sociais da memória, fixados nos espaços lembrados trazem ao 
presente a cultura e a sociabilidade de outrora". A memória passa a ser uma aliada na significação e ressignificação da cultura, pois os traços culturais de uma sociedade que são vivenciados pelos grupos são transmitidos de geração em geração.

Segundo Bosi (1987, p.333), cada geração tem a memória e acontecimentos que permanecem como pontos de demarcação e de sua história. Para Pollak (1989), a memória pode sobreviver ao desaparecimento das civilizações, uma vez que esta se alimenta de referências culturais, literárias ou religiosas. Deste modo, lembrar significa buscar na memória as itinerâncias e experiências vividas, como bem coloca a professora em formação no fragmento do seu memorial, ao relembrar sua vida na universidade.

[...] Hoje, relendo, acho graça de alguns momentos descritos por mim. Confesso que a leitura desse material me remeteu a outras memórias [...]. Lembrei do meu primeiro dia na Universidade, o primeiro trabalho apresentado, as amizades que fiz, os encontros de estudo, os professores preferidos e tantas outras histórias vivenciadas durante os oito semestres cursados na Universidade. (Maria ${ }^{3}$ Memorial, 2019).

Para Maria, a memória se apresenta como algo fluído e que segue um fluxo dinâmico a partir das construções do sujeito. Este fluxo parece seguir uma ordem cronológica de acontecimentos, como descritos pela narrativa da professora. A memória consegue fazer sentimentos outrora vividos serem sentidos novamente, a partir do momento em que é rememorado, fato observado nas palavras de Maria quando diz: “Hoje, relendo, acho graça de alguns momentos descritos por mim" Maria - Memorial, 2011). A memória parece ser uma possibilidade de constituição e reconstituição dos sentidos vividos.

Com base nos estudos realizados por Jedlowski (2003) sobre temas e problemas presentes voltados à temática da memória, o autor defende para uma noção contemporânea de memória relacionada a uma rede de interrelações em que o passado não permanece estático, sendo continuamente selecionado e recriado diante das questões e necessidades individuais e sociais do tempo presente, numa relação estreita com o universo cultural dos sujeitos.

\footnotetext{
${ }^{3}$ Nome fictício dado à colaboradora da pesquisa, com objetivo de preservar a identidade do sujeito, de acordo
} ao que preconiza o CEP para pesquisas com seres humanos. 
O que nós chamamos de memória é uma rede complexa de atividades, cujo estudo mostra que o passado nunca permanece tal e qual, mas é sempre selecionado, filtrado e reestruturado pelas interrogações e pelas necessidades do presente, tanto no nível individual quanto no nível coletivo. (JEDLOWSKI, 2003, p. 217).

Pode-se considerar, portanto, a memória como objeto de suporte na busca de ressignificação do passado. "Lembrar não é reviver, mas refazer, reconstruir, repensar, com imagens e ideias de hoje, as experiências do passado." (BOSI, 1987, p.17). Sendo a memória uma aliada no desenvolvimento do papel transformador/reconstrutor do homem no ambiente em que vive, pode-se dizer que, durante o processo de formação do sujeito social, histórico e cultural, um dos elementos que possibilita ao indivíduo um envolvimento maior com a sociedade é a cultura.

Para Chaui (1997), a cultura está presente nas relações sociais no dia a dia de uma sociedade. Ainda de acordo com esta autora, é através de signos que os seres humanos são capazes de relacionar a realidade vivida com o tempo passado. Alerta Gomes (2008, p.40) que, no processo de transmissão, que se dá no tempo, e também no espaço, ela pode criar novos significados e, portanto, mudar. Para o autor, a cultura tem meios e instituições de autopreservação e conservação que lhe permitem funcionar com estabilidade - e, por conseguinte, dar confiança aos indivíduos que a vivenciam. Chaui (1997) chama a atenção para o fato de que é preciso considerar a dimensão coletiva e/ou social da memória, ou seja, a memória gravada em monumentos, documentos e relatos da história de dada sociedade. Em direção semelhante, Diehl (2002) assinala o caráter histórico e cultural da memória. Assim, ele pontua:

Pelo senso comum, a memória está intimamente ligada às tradições familiares, grupos com suas idiossincrasias peculiares. Nesse nível, ela representa possibilidades de aprendizagem e de socialização, expressando assim continuidade e identidade daquelas tradições. [...] A memória, por também ter características coletivas, assume funções tais como de identificação cultural, de controle político-ideológico, de diferenciação e de integração. (DIEHL, 2002, p.117).

Na construção social do sujeito, seja ela coletiva ou individual, a memória está vinculada a aprendizagens e representações oriundas da inserção desse sujeito nos mais 
variados grupos sociais. A memória se presentifica como um dispositivo de constituição e reconstituição das histórias de vida, de formação e de atuação profissional. Sobre este aspecto, Maria expõe que:

[...] É na graduação que vivenciamos com mais intensidade a pluralidade cultural existente na sociedade. É outro mundo. As experiências pelas quais passamos enquanto graduandos contribuem diretamente para nosso amadurecimento pessoal e profissional. A todo o momento somos estimulados pelos professores a refletir, discutir e agir criticamente. A universidade permite que a aprendizagem não se concentre apenas nas salas de aula, mas em todos os espaços em que exista troca de informação. (Maria - Memorial, 2019).

Maria traz para a cena a questão da memória enquanto elemento fundante da produção de conhecimentos e saberes da sociedade ao que ela intitula de pluralidade cultural. A memória é, portanto, lugar de produção reflexiva que se faz das experiências vivenciadas no âmbito da formação. É o lócus em que a aprendizagem é significada e ressignificada por cada lembrança que emerge como fundante para a produção de um saber que é cultural, pois é vivido no seio da sociedade, pelas relações e produções que se fazem com o outro e consigo mesmo. No caso da docência, isso ocorre, também, pelos sentidos vividos nos percursos de formação que o sujeito vivencia ao rememorar e significar por meio da escrita, situação típica que se evidencia na produção de um memorial. Para Maria, isso se visibiliza pelo que ela compreende sobre o papel da universidade e da formação que logrou em seu percurso formativo. Trata-se, portanto, de uma memória que se fundamenta no vivido, no experienciado, no que ganha notoriedade para o ser, por meio de lembranças que abrem espaço para a construção de novas aprendizagens.

Apesar de toda a discussão sobre a importância da memória para uma sociedade, Chaui (1997) acredita que em nossa sociedade [atual] a memória é valorizada e desvalorizada. É valorizada com a ascensão dos meios de registros e gravação (computadores, fitas cassetes, vídeos, livros) e das instituições que os preservam (museus, bibliotecas...). E, é desvalorizada por não ser considerada um meio de se desenvolver o conhecimento. Diehl (2002, p.117) esclarece que a memória, como qualquer outra fonte histórica, sofre de uma fraqueza, que é seu desgaste ao longo do tempo, pois: 
Ela vai perdendo força, capacidade explicativa, capacidade de informar, torna-se transparente, sem pontos de referência substantiva para manter suas funções, como descrevemos acima. [...] A perda de significação pelo desgaste tem sua origem na forma de representação da concepção de tempo histórico. (DIEHL, 2002, p. 118).

Porém, segundo Horta (2008, p.112), quanto mais ricas e diversificadas as experiências vividas e compartilhadas por um grupo de pessoas vivendo em comunidade, mais rica será a memória ou rememoração. Aspecto que pode contribuir para evitar o desgaste que a memória sofrerá ao longo do tempo, pois se pode compreender que a memória é construída a partir das experiências vividas pelos sujeitos de uma determinada comunidade. Neste sentido, emerge o memorial como um dispositivo de constituição da memória do que é vivido, do que é constituído na travessia formativa de um sujeito, sobretudo em se considerando um espaço/tempo em que as lembranças vão se interrelacionando e produzindo novos sentidos, novas formas de apreender e depreender o que é cultural, o que deve ser preservado e refletido pelo próprio sujeito.

Portanto, pode-se alegar que a memória precisa ser constantemente constituída, e essa atualização poderá ser mantida através de textos, narrativas, fotografias, dentre outros recursos/dispositivos, transformando-os em fonte histórica, ou seja, instrumento de preservação cultural, possibilitando assim uma rememoração das experiências do passado, sejam elas individuais ou coletivas, com intenção de conservar suas bases a fim de não se perder no tempo conhecimentos e identidades. Compreende-se, assim, conforme Silva (2008, p.89), que seja transmitida a vontade de aprender, vivenciar, compreender, repassar e reinventar as tradições.

Sendo a memória e a cultura fundamentais para o desenvolvimento do homem no ambiente, pode-se considerar que as narrativas (auto)biográficas caracterizam-se como dispositivo importante de/para formação do conhecimento e dos saberes. "Desta forma, as narrativas constituem-se como singulares num projeto formativo, porque se assentam na transação entre diversas experiências e aprendizagens individual/coletiva." (SOUZA, 2007a, p.40). O trabalho (auto)biográfico permite que o professor, durante o processo de formação continuada, identifique aspectos e fatores que contribuíram, ou não, na sua escolha profissional estabelecendo relação direta com suas itinerâncias pessoais. 
Segundo Silva (2020), a contribuição da abordagem (auto)biográfica é possibilitar ao sujeito o conhecimento de si que se fundamenta em um modelo epistemológico concebido a partir da produção de narrativas que, entre outros papéis, têm a função de reconstruir o momento já vivido, em um outro tempo e dimensão estrutural, que já não é mais a vivida, mas, sim, a narrada. Esse outro tempo só se constitui pela possibilidade da memória, da existência de uma condição de rememorar, e disso, poder construir a narrativa de vida, de formação, de atuação profissional, ou qualquer outra que seja. É dessa condição, que o memorial se insurge como mecanismo de produção de sentidos sobre o vivido, o rememorado, gerando, para quem o faz, a produção de impressões que são singulares, que são oriundas das tessituras e enredamento da ação de narrar e de trazer, portanto, a memória à baila.

\section{NAS PÁGINAS DO MEMORIAL... AS IMPRESSÕES SINGULARES}

[...] reconhecer que os professores de profissão são sujeitos do conhecimento é reconhecer, ao mesmo tempo, que deveriam ter direito de dizer algo a respeito de sua própria formação profissional [...] (TARDIF, 2012, p.240).

Esta epígrafe de Tardif (2012), quando considera que o professor precisa dizer algo sobre si, pode-se relacionar a uma produção mais intimista - um registro (auto)biográfico, algo que apresente o sujeito e suas itinerâncias pessoais e coletivas, bem como suas experiências profissionais. "Os diários biográficos" (SOUZA, 2007a, p.3) oferecem uma seara de informações que auxiliam na compreensão da constituição do sujeito, pois buscam na memória as reminiscências do processo de escolarização e experiências pessoais que refletem no âmbito profissional.

Atualmente a utilização do trabalho (auto)biográfico no contexto educacional, especialmente nos cursos de formação continuada, de acordo com pesquisas realizadas, em bancos digitais de produção científica, sobre a temática, tem se revelado um importante instrumento para a construção da identidade docente e autoafirmação profissional, pois, como afirma Josso (2002, p.29), a “[...] abordagem biográfica do processo de formação, implica diretamente o aprendente em três dimensões existenciais: 
a sua consciência de ser psicossomático ou 'homo economicus', a sua consciência de 'homo faber' e a sua consciência de 'homo sapiens' [...]”.

Para Souza (2007a), a narrativa (auto)biográfica - ou, mais especificamente, o relato de formação - oferece um terreno de implicação e compreensão dos modos como se concebe o passado, o presente e, de forma singular, as dimensões experienciais da memória de escolarização e de formação. Ainda para este autor, é através dessa "biografia" construída de si que o sujeito produz um conhecimento acerca de si próprio, e do ambiente onde está inserido, destacando o pertencimento àquele lugar.

A cultura, o dia a dia, a crença, o trabalho... tudo compõe o sujeito enquanto "construtor" da sua história e, "[...] os saberes oriundos da experiência de trabalho cotidiana parecem constituir o alicerce da prática e da competência profissionais, pois essa experiência é, para o professor, a condição para a aquisição e produção de seus próprios saberes profissionais" (TARDIF, 2012, p. 21). Para este autor, o saber docente pode definirse como um saber plural, composto de saberes provenientes da sua formação profissional e "saberes disciplinares, curriculares e experienciais" (p.36), pois o saber do professor "[...] é adquirido no contexto de uma história de vida e de uma carreira profissional." (TARDIF, 2012, p.19). Deste modo, salienta Souza (2007a) que:

O trabalho, centrado nas histórias de vida, diários biográficos e narrativas de formação, adota, além da reflexibilidade, outros aspectos e questões relativas à subjetividade e à importância de se ouvir a voz do professor ou compreender o sentido da investigação-formação. (SOUZA, 2007a, p.3).

Para este autor, esse processo de pesquisa está relacionado ao movimento de formação ao longo da construção de sua própria história, e que toma a “[...] experiência do sujeito adulto como fonte de conhecimento e de formação, denominada de 'abordagem experiencial" (SOUZA, 2007a, p.3).

Tardif (2012, p.232) compartilha da ideia de Souza (2007a) quando nos esclarece que “[...] o professor é considerado o sujeito ativo de sua própria prática", sendo assim, ele apresenta sua prática e a cria a partir de suas experiências, de sua cultura e de seus valores, e seu saber está diretamente relacionada com sua história de vida e sua prática docente decorre do entrelaçamento dos saberes que constituem a pessoa e o profissional que se tornou no decurso de suas experiências. 
Acerca desta mesma discussão, pesquisas recentes de Vieira, Vieira e Pasqualli (2014) e Pasqualli e Cassaro (2020), corroboram com os escritos de Tardif, ao destacar que a importância de, ao fazer perguntas aos professores sobre seus saberes, os estimular a contar suas memórias do saber-ensinar e, por meio de seus relatos pessoais e profissionais significativos, apresentar pontos de vista acerca da constituição de sua identidade docente.

Nessa mesma direção, Silva (2020) considera que as narrativas (auto)biográficas fazem emergir os saberes experienciais dos professores, sobre os quais a reflexão e a constituição de novos sentidos ganham forma pela condição de se rememorar e ressignificar o vivido. Em outras palavras, as narrativas evidenciam os modos próprios de como os professores produzem seus saberes, que além de serem explicitados pela ação de narrar, são ressignificados e abrem espaços para a produção de novos saberes, de modo singular e ao mesmo tempo plural.

De acordo com Tardif (2012, p.33) o saber docente constitui-se de diversos saberes originado de diferentes fontes, pois, ainda segundo o autor, "o saber dos professores é plural e também temporal” (p.19). Esses saberes são adquiridos através de experiências pessoais, coletivas, nos mais diferentes espaços, como os familiares, escolares e os acadêmicos. Em contrapartida, as exigências contemporâneas demandam que os docentes se apropriem de conhecimentos pré-estabelecidos de acordo com a necessidade intelectual social.

No processo de formação, desenvolver conhecimento a partir de saberes estabelecidos por uma matriz curricular é uma tarefa difícil, pois a mobilidade que é necessária para a aquisição do conhecimento no processo formativo é praticamente nula se não for relacionada com os saberes do cotidiano, das experiências vivenciadas no contexto pessoal.

Tardif (2012, p.35) nos esclarece que "todo saber implica um processo de aprendizagem e de formação". Portanto, é imprescindível desarticular os saberes cotidianos dos saberes científicos na formação do profissional, sobretudo no que se refere à educação. É importante sinalizar que a pessoa se torna um profissional quando articula os saberes “[...] oriundos da formação profissional e de saberes disciplinares, curriculares e experienciais" (TARDIF, 2012, p.36). Dos diversos tipos de saberes que permeiam a 
formação docente, é o saber experiencial o qual se fundamenta toda a discussão neste artigo, pois é este saber - que tem como base as experiências cotidianas - que é identificado nas histórias de vida construídas pelos professores. Neste sentido, Maria, ao rememorar o seu processo formativo inicial, assim rememora:

[...] Não foi fácil conciliar a pesquisa com a graduação, pois o projeto era voltado à pesquisa de campo, sendo necessário realizar viagens até nosso "objeto de estudo". Em alguns momentos tive que optar entre faltar aulas para viajar ou não viajar para assistir as aulas. A pesquisa me rendeu bons frutos, entre eles o tema de monografia apresentada como trabalho de conclusão de curso. Apesar dos percalços, considero que a experiência no núcleo de pesquisa e na iniciação científica contribuíram para meu desenvolvimento intelectual e profissional. (Maria - Memorial, 2019).

Neste excerto narrativo, Maria pontua os momentos difíceis que passou quando tinha que optar por uma atividade formativa em detrimento de outra e como foi difícil o seu processo de formação inicial, mas ao final considera a sua inserção na iniciação científica uma experiência bastante importante na construção da sua identidade profissional. Neste aspecto, a aprendizagem experiencial da iniciação científica, por exemplo, é rememorada e significada como lócus, também, da produção de sua identidade intelectual e profissional. Isso implica em reconhecer que, conforme assevera Silva (2017), a aprendizagem experiencial é produtora de significações e ressignificações de saberes que emergem do campo experiencial, explicitado pelo viés da narrativa. Portanto, o lugar da narrativa e do memorial, é lugar de produção de sentidos, de revelar, desvelar, significar e ressignificar as experiências de vida, formação e desenvolvimento profissional.

Uma discussão interessante sobre a palavra experiência é abordada por Larrosa (2002) em seu texto “Notas sobre a experiência e o saber de experiência”, quando ressalta que “[...] a experiência é o que nos passa, o que nos acontece, o que nos toca. Não o que se passa, não o que acontece, ou o que toca. A cada dia se passam muitas coisas, porém, ao mesmo tempo, quase nada nos acontece" (p.21). Para este autor, é necessário que algo nos toque e que algo aconteça para validar a experiência.

Tardif (2012, p. 39) defende que os saberes experienciais "brotam da experiência e são por ela validados", pois: 
Os saberes experienciais são o conjunto de saberes atualizados, adquiridos e necessários no âmbito da prática da profissão docente e que não provêm das instituições de formação nem dos currículos. [...] São as situações que permitem compreender os saberes da experiência. (TARDIF, 2012, p. 49, 52).

Portanto, na docência, é comum que os professores considerem o saber adquirido com a experiência profissional "constitui a base de sua competência" e que esta decorre do entrelaçamento dos saberes científicos com os do cotidiano, pois os saberes experienciais são permeados de símbolos, valores, sentimentos e atitudes. Nas palavras de Tardif (2012, p.52), "são as situações que permitem compreender os saberes da experiência. [...] e tais situações, os professores são levados a tomar consciência de seus próprios saberes experienciais". Por tomar consciência, o leitor deve entender tal expressão como a condição de produção de novos sentidos, como produção da potência e alargamento de possibilidades de entender o efeito de uma aprendizagem que é baseada na experiência docente, logo na aprendizagem experiencial.

De acordo com Josso (2010, p. 40), “os contos e as histórias da nossa infância são os primeiros elementos de uma aprendizagem que sinalizam que ser humano é também criar as histórias que simbolizam a nossa compreensão das coisas da vida". Essa perspectiva sinaliza que o sujeito aprende a partir da reflexão sobre a sua história de vida, e que ao longo do tempo sua concepção de mundo/vida varia de acordo com cada experiência vivida. Esta autora ainda defende que:

Se os nossos comportamentos socioculturais são esquemas relacionais de base, que foram aprendidos por meio de experiência, e exercidos e integrados em rituais relacionais próprios de cada comunidade, eles também são remodelados pelos temperamentos, pela sensibilidade, pela infinidade dos matizes que manifestam essa originalidade que nos surpreendem na sua redefinição desses esquemas. (JOSSO, 2010, p. 39).

Tal recorte evidencia que o sujeito produz um conhecimento sobre si (SOUZA, 2006) e sobre o coletivo através das experiências vividas reconhecendo-as no plano de pertencimento do ambiente em que está inserido. Portanto,

[...] "o saber-ensinar" na medida em que exige conhecimentos de vida, saberes personalizados e competências que dependem da personalidade dos atores, de seu saber-fazer pessoal, tem suas origens na história de vida familiar e escolar dos professores de profissão. (TARDIF, 2012, p. 79). 
Sendo assim, de acordo com Tardif (2012, p.73), "trabalhos biográficos permitem identificar experiências familiares, escolares ou sociais, como fontes de suas convicções, crenças ou representações". Tais elementos são bastante significativos, pois surgem como uma fonte de influência que possibilita ao indivíduo estabelecer sua relação com o meio no qual está inserido.

\section{OS FRAGMENTOS MEMORÍSTICOS NÃO SE CONSTITUEM APENAS RECORTES DE UMA HISTÓRIA}

O sucesso das histórias de vida [...] nem sempre tem tido como suporte uma adequada reflexão teórica e metodológica [...] porque o campo da formação de formadores não pode limitar-se apenas às dimensões técnicas e tecnológicas. (JOSSO, 2010, p. 19).

As histórias de vida que têm o professor como personagem principal revelam-se uma fonte que, segundo Souza (2007b, p. 69), “leva a reconhecer os saberes construídos pelos docentes", pois esse é um dos dispositivos que permitem ao sujeito explorar aspectos sobre si, sobre os outros e o ambiente ao qual está inserido - nesse caso no plano educacional. Para Josso (2010, p. 65), “o trabalho biográfico sobre as narrativas de vida, em cointerpretação com seu autor, põe em evidência, sob a forma de peregrinação 'vital', a procura de um saber-viver". Assim, rememora Maria:

[...] Existe um cheiro que me faz lembrar meus primeiros anos na escola. É o cheiro de álcool que vinha impregnado nas atividades "rodadas" no mimeógrafo 4 . Na maioria das vezes, as tarefas vinham manchadas. Eu adorava aquele "cheirinho", e cobria as vogais pontilhadas com o maior cuidado. (Maria - Memorial, 2019).

A memória possibilita a inserção de outros sentidos para o espaço escolar, para o que a professora, na condição de estudante vivenciou. Tal lembrança, expressa um saber experiencial que se logra na escola pela ação específica que professores realizavam, ou seja, dar aos estudantes tarefas mimeografadas. É a lembrança do cheiro que ativa o valor

\footnotetext{
4 Aparelho de impressão, elétrico ou manual, com que se reproduzem cópias de páginas escritas, datilografadas ou de desenhos, sobre uma matriz de papel metálica, chamada estêncil (Dicionário Escolar da Língua Portuguesa, 2008).
} 
da aprendizagem experiencial de cobrir as vogais e de aprender e ter gosto por fazer isso. Essa boa lembrança, impacta num modo peculiar de atribuir sentido ao momento vivido e ter, na condição de professora, a perspectiva de ofertar, a seus estudantes, aprendizagens que também sejam experienciais e exitosas. Neste recorte, é possível identificar a relação que Maria estabeleceu ao rememorar seus primeiros anos no espaço escolar e a sensação de prazer que tal memória proporcionou. A utilização do memorial como dispositivo na construção da memória, sugere que o ato de lembrar produz um saber experiencial que é impresso no processo de formação continuada, portanto considerar que a escrita (auto)biográfica é um instrumento importante nesse processo é acreditar que as narrativas contribuem diretamente na/para formação do sujeito.

Enfatiza Souza (2007b) que "A escrita da narrativa abre espaços e oportuniza, às professoras e professores em processo de formação, falar-ouvir e ler-escrever sobre suas experiências formadoras, descortinar possibilidades sobre a formação através do vivido". (p.69). De fato, concordamos com Souza (2007b) quando ele enfatiza que o trabalho (auto)biográfico não se limita apenas a identificar como desenvolve-se o processo de formação do docente ao longo da trajetória de vida, mas também a identificar como o sujeito se constitui enquanto ser sociocultural. Sobre estas questões, Maria enfatiza que:

[...] Há alguns anos, ainda na graduação - para ser mais precisa, no primeiro semestre do curso de Licenciatura em Pedagogia -, escrevi um memorial. Hoje, relendo-o, acho graça de alguns momentos descritos por mim. Confesso que a leitura desse material me remeteu a outras memórias... Lembrei do meu primeiro dia na Universidade, o primeiro trabalho apresentado, as amizades que fiz, os encontros de estudo, os professores preferidos e tantas outras histórias vivenciadas durante os oito semestres cursados na Universidade. Agora, anos passados e já no curso de pós-graduação em Docência do Ensino Superior, me vejo na arte de rememorar. O memorial foi reescrito. Acredito que este foi um trabalho feito com mais maturidade do que a primeira versão, realizada ainda no início da graduação. $O$ tempo passou, a idade também, e as experiências foram me transformando em quem sou hoje. (Maria - Memorial, 2019).

Como defende Diehl (2002), a memória faz ativar as lembranças de uma tradição cultural e social que está ligada aos ritos da formação vivenciada pelo sujeito. Se isso é verdade, é tão verdadeiro o que afirma Silva (2020) ao considerar que as narrativas (auto)biográficas possibilitam fluir as aprendizagens experienciais e culturais que estão emanadas nas histórias de vida, e no caso do estudo em tela, nas histórias de formação de 
Maria. O reescrever o memorial significa ativar as lembranças e desenvolver novas aprendizagens experienciais, que não só são lembradas e registradas, mas construídas no momento de produção do próprio memorial, no momento da ação de narrar (SILVA, 2006).

Em sua narrativa, Maria produz e retrata um exercício reflexivo de pensar sobre a sua própria formação, de pensar na construção da pessoa e da profissional que ela tem se tornado, pois o relato de vida é um trabalho de reflexão que, para Josso (2010, p.67), é um exercício "pensante, sensível, imaginante, comovendo-se, apreciando, amando", que possibilita obter a ideia das transformações culturais/sociais que o sujeito passou de forma individual e coletiva pelas quais ele experienciou, uma vez que:

A prática das histórias de vida orientada pela identificação da formação e dos seus processos (modalidades, dinâmicas, gêneros de aprendizagem e de conhecimento construídos ao longo da vida) permitiu revelar o conceito de experiências de vida como fundamento do processo de formação. (JOSSO, 2010, p. 266).

Vale ressaltar que o trabalho (auto)biográfico e a narrativa de formação são dispositivos que atuam como mecanismos de investigação-formação, uma vez que as experiências pelas quais os docentes passam/passaram durante o processo de formação inicial ou continuada - são formadas a partir de "um conjunto de atividades, de situações, de relações, de acontecimentos como contextos formadores" (JOSSO, 2010, p. 276).

É preciso compreender que as histórias de vida se firmam enquanto "método/técnica de investigação/formação" (SOUZA, 2007b, p.65), pois elas contribuem na interpretação dos sentidos e significados das experiências, sejam elas individuais e coletivas (SOUZA, 2007b). Sobre os sentidos e significados das experiências vivenciadas no processo de formação continuada no curso de especialização em Docência do Ensino Superior, Maria rememora que:

[...] Resolvi iniciar a pós-graduação para dar continuidade ao que foi iniciado na graduação. A escolha dessa especialização partiu do desejo em atuar na área de docência superior, bem como trabalhar com pesquisas. Quero ser professora do ensino superior - ainda que no momento desempenhe função contrária à minha formação. Escolhi o curso com a certeza de que este seja o primeiro passo para atingir minhas metas. $O$ mestrado e doutorado estão nos meus planos desde a graduação. Sinto a necessidade de retomar o tema de pesquisa que trabalhei na graduação e o meio para retomar a discussão é ser pesquisadora, mas, claro, sem deixar de ser professora. No próximo ano concluo a especialização, o que vai 
acontecer depois eu não sei. É assim que findo esse memorial, não com um ponto final, mas com reticências. É apenas o começo. (Maria - Memorial, 2019).

Para esta professora em formação continuada, a escrita (auto)biográfica a estimula para uma tomada de consciência da sua postura e de suas ações frente aos desafios pelos quais passou/passa durante seu processo de formação - inicial e continuada - e essa consciência crítica é refletida na sua prática. A narrativa constitui o lócus da reflexão sobre as perspectivas formativas, sobretudo pelos sentidos do que a formação representa para ela. A escrita do memorial se assemelha como a possibilidade da travessia formativa, ou seja, nunca se encerra, nunca se esgota em si mesma, pois o sujeito é vivo e nessa vivacidade a formação continuada é perene, como perene é também a condição de aprender experiencialmente e de narrar para si mesma os seus próprios desafios, anseios e as aprendizagens logradas até o momento vivido. É no cenário da perenidade da possibilidade de aprender, que Maria continua a nos dizer sobre os desafios encontrados em sua travessia formativa. Assim, ela narra:

\begin{abstract}
Muitos desafios surgiram ao longo do curso, mas nunca pensei em desistir. Foi nos estágios supervisionados que conheci, de fato, a realidade educacional, principalmente a pública. Visitei instituições de ensino localizadas em zonas periféricas, escolas, cujas merendas servidas para os alunos era um pedaço de cocada, escolas mal iluminadas, depredadas, professores pouco comprometidos... Visitei também escolas organizadas, com professores muito comprometidos, merenda escolar de qualidade, salas amplas, arejadas e iluminadas... Foi o momento mais difícil de todo o processo de formação inicial para mim. Após cada estágio chegava em casa com sentimento de impotência, me questionando o que poderia fazer para melhorar aquela situação. Era fácil chorar! Foi um tempo de aprendizado pessoal, de saber controlar as emoções, de definir se era este o caminho a seguir. (Maria - Memorial, 2019).
\end{abstract}

Segundo Josso (2010, p.297), “os elementos biográficos são, então, reunidos e organizados em história segundo a lógica de um eu que imagina elos temporais significativos entre o passado, o presente e o futuro". Ao longo da escrita deste trabalho, essa "história segundo a lógica de um eu" fica evidenciada nos recortes do memorial apresentados entre os parágrafos, por meio dos quais a autora, professora em formação continuada, ao rememorar suas itinerâncias, as apresenta em ordem de significância de aprendizagens, obedecendo não a uma ordem meramente cronológica, mas a ordem de situações, vivências e experiências que lhe são significativas, sobre as quais a narrativa 
permite destacar. Nessa perspectiva analítica é possível compreender o que nos diz Josso (2010), quando considera que:

\begin{abstract}
As histórias de formação são, sem sombra de dúvida, uma das mediações possíveis para redescobrir essas dimensões "esquecidas", para mostrar como é que elas continuam a estar vivas dentro de nós, como alimentam o nosso "ganhar forma", para as reinvestirmos conscientemente como tantas outras vias possíveis de interpretação da significação da nossa existência e da direção que entendemos dar à nossa busca de uma arte de viver em ligação e partilha. (JOSSO, 2010, p. 300).
\end{abstract}

As discussões em torno da pesquisa (auto)biográfica no campo educacional intensifica a ideia da necessidade do sujeito de se autoavaliar e tomar consciência do processo de formação e suas aprendizagens. Trata-se, portanto, de considerar o memorial, logo as narrativas, como espaço de construção de significações da existência do humano, da existência das aprendizagens experienciais, que segundo Silva (2017) são logradas nos percursos de vida, formação, atuação profissional etc. São as aprendizagens que estão vivas dentro de cada um e que se enredam e produzem novos sentidos pela narrativa, pela condição de ter na memória as vivas lembranças do vivido, do que de fato faz sentido para cada sujeito.

Sem dúvida a utilização do trabalho (auto)biográfico como instrumento formativo pessoal/profissional se destaca como um valioso objeto de pesquisa no campo educacional, especialmente no que tange sua colaboração na/para a construção da identidade docente, que entre outros atributos, se constitui no movimento da vida, das experiências e das vivências que cada um logra na ação e situação em que se encontra. No caso do estudo em tela, na vida, na formação continuada e na docência de Maria.

\title{
A GUISA DE CONSIDERAÇÕES
}

O presente estudo possibilitou compreender como o memorial se constitui como um dispositivo interessante para analisarmos os sentidos que o próprio sujeito constrói ao rememorar sua história de vida, formação e de atuação profissional. A narrativa emergiu como uma possibilidade de produção reflexiva e autorreflexiva que o sujeito produz de si e de seus percursos. Nesta seara, a narrativa não se constituiu como uma mera 
representação que o sujeito faz de si e de sua travessia no campo educacional. Muito pelo contrário, a narrativa (auto)biográfica possibilitou que a professora Maria desenvolvesse algumas compreensões sobre si e sobre os significados que ela mesma tem atribuído às lembranças que, narrativamente, os traz à baila e cria novos momentos de aprendizagens experienciais.

A formação continuada se constituiu em uma dupla possibilidade de efetivação no presente estudo. Uma por meio da qual a professora narrou suas aprendizagens no curso de pós-graduação que realizou no campo da docência universitária; a outra pela produção do próprio memorial que, além de dispositivo metodológico de uma pesquisa da pósgraduação que a professora participou, se concretizou como espaço de formação e de autoformação por meio do qual a professora, colaboradora do estudo, pode significar, ressignificar e explicitar as aprendizagens experienciais que logrou no momento da própria escrita.

Nessa direção, a memória foi tomada como elemento fundante para a produção da ação do rememorar, em que as lembranças criaram condições reflexivas para a produção de novos sentidos para a vida, sobretudo para a formação continuada e para a atuação profissional. A reflexividade foi concebida como aspecto basilar para o que denominamos de tomada de consciência, que nada mais significa do que ter para si a consciência de que a narrativa é reveladora e criadora de aprendizagens experienciais.

Assim sendo, o presente estudo nos possibilita concluir que, mesmo não sendo uma metodologia inovadora, dado a sua recorrência no campo da formação de professores, como asseveram Souza (2006, 2007a e 2007b) Josso (2010) e Silva (2017 e 2020), a (auto)biografia enquanto metodologia de compreensão de práticas, saberes e processos formativos de professores continua sendo potente, e revelando as singularidades de cada processo vivenciado, pois cada sujeito é único e apresenta um modo próprio e peculiar de compreender e explicitar as suas aprendizagens experienciais no campo da educação. Tal situação se deve, sobretudo ao lugar da escrita do memorial como espaço de produção de saberes experienciais, que se tornam movimentos formativos do próprio sujeito

Nessa perspectiva analítica, os resultados dessa pesquisa sugerem que as discussões em torno da pesquisa (auto)biográfica no campo educacional intensifica a ideia da necessidade do sujeito de se autoavaliar e de produzir sentido sobre o processo de 
formação e sobre as aprendizagens desenvolvidas no percurso formativo. Com o estudo, foi possível evidenciar que a utilização do trabalho (auto)biográfico como instrumento formativo pessoal/profissional se destaca como um valioso objeto de pesquisa no campo educacional, especialmente no que tange sua colaboração na/para a construção da identidade docente, que se faz e refaz nos percursos da vida e no modo próprio como cada sujeito logra vivências, gerando para si as aprendizagens experienciais no campo da educação.

\section{REFERÊNCIAS}

ARANHA, Maria Lúcia de Arruda. História da Educação e da Pedagogia: geral e Brasil. 3. ed. rev. e ampl. São Paulo: Moderna. 2006.

BOSI, Eclea. Memória e sociedade: lembranças de velhos. 2. ed. São Paulo: T. A. Queiroz, Ed. da USP, 1987.

CHAUI, Marilena de Souza. O conhecimento - A memória. In: CHAUI, Marilena de Souza. Convite à filosofia. 9. ed. São Paulo: Ática, 1997. p. 125-130.

DIEHL, Astor Antônio. Memória e identidade: perspectivas para a história. In: DIEHL, Astor Antônio. Cultura historiográfica: memória, identidade e representação. Bauru: EDUSC, 2002. p. 111-136.

GIL, Antônio Carlos. Métodos e técnicas de pesquisa social. 3. ed. São Paulo: Atlas, 1991. $207 \mathrm{p}$.

GOMES, Mercio Pereira. Cultura e seus significados. In: GOMES, Mercio Pereira. Antropologia: ciência do homem: filosofia da cultura. São Paulo: Contexto, 2008. p. 33-51.

HORTA, Maria de Lourdes Parreiras. Os lugares da memória. In: SILVA, René Marc da Costa. (org). Cultura popular e educação: salto para o futuro. Brasília: Ministério da Educação, 2008. p. 111-118.

JEDLOWSKI, Paolo. Memórias: temas e problemas da sociologia da memória no século XX. Campinas: Pro posições, v. 14, n.1, p. 217-234, 2003.

JOSSO, Marie-Christine. Experiências de vida e formação. São Paulo: Cortez, 2010.

LARROSA, Jorge Bondia. Notas sobre a experiência e o saber de experiência. Rev. Bras. Educ., Rio de Janeiro, n. 19, abr. 2002. Disponível em < http://www.scielo.br/pdf/rbedu/n19/n19a02.pdf >. Acesso em: 16 dez. 2019. 
Revista do Programa de Pós-Graduação em Educação da Unochapecó

ISSN 1984-1566 (on-line) ISSN 1415-8175 (impressa)

PASQUALLI, Roberta; CASSARO, Clovis Alceu. Inovações Pedagógicas na Pós-Graduação na modalidade de Educação a Distância no Instituto Federal de Educação, Ciência e Tecnologia de Santa Catarina. Revista de Ensino, Educação e Ciências Humanas. v. 21 n. 2, p. 173-180, 2020. Disponível em:

https://revista.pgsskroton.com/index.php/ensino/article/view/7587. Acesso em: 16 nov. 2020.

POLLAK, Michael. Memória, Esquecimento, Silêncio. Estudos Históricos, Rio de Janeiro, v.2, n. 3, 1989. Disponível em:

<http://bibliotecadigital.fgv.br/ojs/index.php/reh/article/view/2278/1417 > Acesso em: 13 nov. 2019.

ROSA, Guimarães. Grande Sertão: Veredas. 3. ed., Rio de Janeiro: José Olympio, 1993.

SILVA, Fabrício Oliveira da. Tessituras constitutivas da abordagem (auto)biográfica como dispositivo de pesquisa qualitativa. Práxis Educativa, Ponta Grossa, v. 15, p. 1-15, 2020 Disponível em: http://www.revistas2.uepg.br/index.php/praxiseducativa. Acesso: mar. 2020.

SILVA, Fabricio Oliveira da. Formação docente no PIBID: temporalidade, trajetórias e constituição identitária. 2017. 220 f. Tese (Doutorado em Educação). Universidade do Estado da Bahia, Salvador, 2017.

SILVA, Maria Aparecida de Moraes. Das mãos à memória - Maria Aparecida. In: MARTINS, Jose Souza; NOVAES, Cornelia Eckert, Sylvia Caiuby. (orgs.). O imaginário e o poético nas ciências sociais. Bauru, SP: EDUSC, 2005. p. 295 - 315.

SOUZA, Elizeu Clementino. História de vida e práticas de formação: escrita de si e cotidiano escolar. In: Série História de Vida de Formação de Professores. Boletim do Salto para o futuro. Brasília: Secretaria de Educação à distância. Ministério da Educação, 2007a. Disponível em: <https://docplayer.com.br/7421087-Historias-de-vida-e-formacao-deprofessores-1.html >. Acesso em: 21 de nov. 2019.

SOUZA, Elizeu Clementino. (Auto)biografia, histórias de vida e práticas de formação. In: NASCIMENTO, AD., e HETKOWSKI, TM., (Orgs.). Memória e formação de professores [online]. Salvador: EDUFBA, 2007b. p. 59 -74. ISBN 978-85-232-0484-6.

SOUZA, Elizeu Clementino. O conhecimento de si. Estágio e narrativas de formação de professores. Rio de Janeiro: DP\&A; Salvador, BA: UNEB, 2006.

TARDIF, Maurice. Saberes docentes e formação profissional. 13. ed. Petrópolis, RJ: Vozes, 2012.

VIEIRA, Marilandi Maria Mascarello; VIEIRA, Josimar de Aparecido; PASQUALLI, Roberta. Formação de professores da educação profissional nos programas especiais de formação 
pedagógica. Revista Brasileira da Educação Profissional e Tecnológica, [S.I.], v. 1, n. 7, p. 43-55, mar. 